Case4: A term newborn was appealed to our emergency service, with dyspnea and supraventricular tachycardia was diagnosed on 13th postnatal day. After intervention, multiorgan failure developed in our patient. At his postnatal day 27, vvHDF was performed. The patient died because of ventilator associated pneumonia.

Conclusion Continuous vvHDF application should be considered in the neonatal period, in cases where it is impossible to apply PD. Due to the technical difficulties in the neonatal period, such application is not common but it is also life saving.

\section{PO-0717 NEONATES WITH PARENTS WHO ARE CHILDREN: WHO CONSENTS?}

H Turnham, J Brierley. Paediatric Intensive Care, Great Ormond Street Hospital, London, UK

\subsection{6/archdischild-2014-307384.1352}

Introduction As neonates do not have capacity those with parental responsibility (PR) usually consent for medical interventions. ${ }^{1}$ A recently delivered mother may be the only person with automatic PR, but might be unavailable in person, especially if the infant has been transferred to another hospital.

Whilst consent can be obtained through telephone ${ }^{2}$ assessing capacity in this situation can be challenging, especially if the parent is under sixteen, and therefore lawfully a child themselves.

Case presentation A baby with bladder extrophy was delivered of a 15-year old undergoing treatment for aplastic anaemia. After transfer to the national urology unit the surgical team obtained consent by phone. On review there was rather limited exploration of mother's ability to understand suggested management and therefore consent.

Discussion Children are afforded the right to consent to medical treatment from 16-years. ${ }^{3}$ Though in Gillick $v$ West Norfolk and Wisbech AHA. ${ }^{4}$ Fraser LJ outlined circumstances where even younger children might consent to oral contraception and Scarman LJ extended it to a general replacement of parental consent as children mature.

It is now accepted that children of any age can consent if they can demonstrate capacity. But, no child has yet been permitted by the Courts to decline medical treatment held to be in their best interests. ${ }^{5,6}$

We can find no recorded cases - e.g. Westlaw-UK - before UK Courts regarding child-parents consenting or refusing treatment for their own child.

Professionals consenting for neonatal interventions need to be aware of the law surrounding child-parents. ${ }^{7}$

\section{REFERENCES}

1 Children Act 1989 Part 1, Section 2, The National Archives, http://www.legislation.gov.uk/ukpga/1989/41/section/2 viewed 10 January 2014

2 Great Ormond Street Hospital, Consent Policy, September 2012

3 Family Law Reform Act 1969, Part 1, Section 1 The National Archives, http:// www.legislation.gov.uk/ukpga/1969/46 viewed January 102014

4 Gillick v West Norfolk and Wisbech AHA [1986] A. C. 112; [1985] 3 W. L. R. 830; [1985] 3 All E. R. 402; [1986] Crim. L. R. 113; (1985) 82 L. S. G. 3531; (1985) 135 N. L. J. 1055; (1985) 129 S. J. 738

5 Re E (A Minor) (Wardship: Medical Treatment) [1993] 1 F. L. R. 386; [1994] 5 Med. L. R. 73

6 Re P (Medical Treatment: Best Interests) [2003] EWHC 2327 (Fam); [2004] 2 F. L. R. 1117; [2004] Fam. Law 716

7 L Fisher-Jeffes, C Barton, F Finlay. (2007) 'Clinicians' knowledge of informed consent', Journal of Medical Ethics, vol. 33, pp.181-184

\section{PO-0718 TEMPERATURE MEASUREMENT DURING BODY-COOLING THERAPY IN NEWBORN BABIES WITH HYPOXIC-ISCHAEMIC ENCEPHALOPATHY}

${ }^{1}$ RDG van der Spek, ${ }^{1}$ RA van Lingen, ${ }^{2}$ BJ Kollen. ${ }^{1}$ Princess Amalia Department of Paediatrics Division of Neonatology, Isala, Zwolle, Netherlands; ${ }^{2}$ Department of General Practice University of Groningen, University Medical Centre Groningen, Groningen, Netherlands

\subsection{6/archdischild-2014-307384.1353}

Background and aims Temperature control during therapeutic hypothermia in newborns with hypoxic ischaemic encephalopathy needs to be monitored with great care since this treatment can cause serious side effects. The temperature measured in the pulmonary artery is considered the 'gold standard'; however, this is not suited to patients in the NICU. A reliable and less invasive method is the temperature measured in the oesophagus. Aim We hypothesised temperature measurements during hypothermia using an oesophageal probe reflects higher temperatures than measurements using a rectal probe.

Methods 20 newborns treated with hypothermia were provided with a continuous rectal temperature probe as well as an oesophageal temperature probe. Both measurements were registered over a period of $72 \mathrm{~h}$ of hypothermic therapy.

Results Linear multilevel regression analysis revealed significant associations between rectal and oesophageal temperatures. We recorded a mean difference per degree between rectal and oesophageal temperatures of $0.12^{\circ} \mathrm{C}$. This difference is $0.17^{\circ} \mathrm{C}$ higher during the cooling phase when compared to the rewarming phase.

Conclusion The differences between oesophageal and rectal temperatures do not result in any clinical effects. Temperature control during hypothermia can be done with either an oesophageal probe or a rectal probe; however, in order to reduce the risk of inadequate cooling due to a defective or dislocated probe, it is safer to use both probes simultaneously.

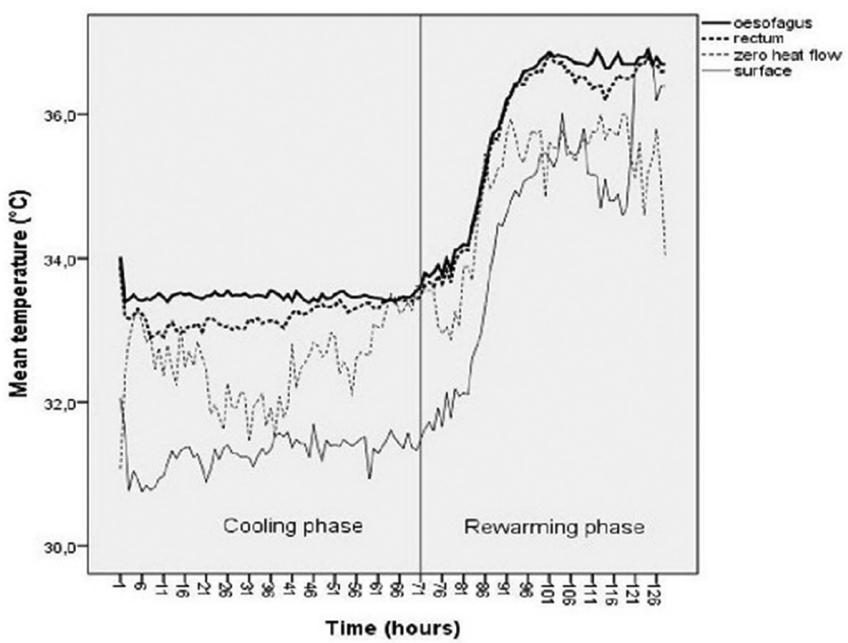

Abstract P0-0718 Figure 1 Oesophageal temperature, rectal temperature, surface temperature and zero heat flow temperature during $72 \mathrm{~h}$ of hypothermic treatment followed by the rewarming period 